\title{
Electron microscopy and atom probe tomography of nanoindentation deformation in oxide dispersion strengthened steels
}

\author{
T.P. Davis ${ }^{*}, 1$, J. Haley ${ }^{1}$, S. Connolly ${ }^{1}$, M.A. Auger ${ }^{1,2}$, M.J. Gorley ${ }^{1}$, P.S. Grant ${ }^{1}$, P.A.J. \\ Bagot $^{1}$, M.P. Moody ${ }^{1}$, D.E.J. Armstrong ${ }^{1}$ \\ ${ }^{1}$ Department of Materials, University of Oxford, Parks Road, Oxford, OX1 3PH, UK \\ ${ }^{2}$ Department of Physics, Universidad Carlos III de Madrid, Leganés, Madrid, Spain \\ *Corresponding Author: thomas.davis@materials.ox.ac.uk
}

\begin{abstract}
Oxide Dispersion Strengthened (ODS) steels are candidates for fuel cladding materials in sodium-cooled fast reactors and for structural materials in nuclear fusion power reactors. The effect yttrium-titanium-oxygen (Y-Ti-O) nano-oxide precipitates within ODS steels have on the micromechanical deformation mechanisms has been investigated. The aim is to assess the extent of any direct link between the Y-Ti-O dispersion and nanoindentation hardness, using electron backscatter diffraction, transmission electron microscopy (TEM), and atom probe tomography (APT) studies of a $\mathrm{Fe}-14 \mathrm{Cr}-3 \mathrm{~W}-0.2 \mathrm{Ti}-0.25 \mathrm{Y}_{2} \mathrm{O}_{3}(\mathrm{wt} \%)$ ODS steel at room temperature. Y-Ti-O nanoclusters had a non-uniform distribution and average number density that ranged from $5.8 \pm 0.1 \times 10^{23}$ to $1.3 \pm 0.1 \times 10^{24} \mathrm{~m}^{-3}$ and Guinier radii ranging from $1.8 \pm 0.2 \mathrm{~nm}$ to $2.1 \pm 0.2 \mathrm{~nm}$. Surprisingly, the local Y-Ti-O distribution did not correlate strongly with the nanohardness, indicating that the dominant hardening mechanisms was at best only weakly related to the Y-Ti-O distribution. Instead, scanning TEM and APT confirmed that the dominant hardening mechanism was due to the grain boundary refinement, and was further enhanced by tungsten enrichment to $\sim 3.5$ at $\%$ at grain boundaries.
\end{abstract}

\section{INTRODUCTION}

Sodium-cooled fast nuclear reactors (a type of Generation IV nuclear reactor [1,2]) fuel cladding material will experience intense neutron irradiation, high temperatures, and corrosive environments that excludes the use of existing generation (II/III+) fuel cladding materials such as zirconium alloys used in current Pressurised Water Reactors [3]. The fuel cladding's primary function is to provide a physical barrier between the fuel and coolant; any failure of this material could result in contaminated coolants and components and system outages. Furthermore, increasing the primary coolant temperature and increasing the fuel burn up fraction are two methods that could significantly improve the efficiency, optimise resource use, reduce nuclear waste, and increase the economic viability of sodium-cooled fast reactors [4]. Unfortunately these methods would also exclude the use of established ferritic-martensitic steels , such as HT9 [5], T91 [5] or EP-450 [6], due to their limited high temperature creep resistance, and austenitic stainless steels, such as Type 316 [5], 15-15Ti (1.4970) [2] or D9 [7], due to their extensive void swelling. New structural materials are therefore required to meet the demands of high temperature coolants, high fuel burn up fraction methods and tolerate the associated increase in neutron flux[8].

Reduced-activation ferritic-martensitic (RAFM) steels, such as F82H $[9,10]$ and EUROFER97 $[11,12]$, are possible candidate structural materials for the breeder blanket, divertor, and other 
structural components within nuclear fusion power reactors. However, like the sodium-cooled fast reactor, nuclear fusion demands the development of new materials that can withstand greater irradiation damage and higher operational temperatures than these RAFM steels [13].

Oxide Dispersion Strengthened (ODS) steels (sometimes called 'nanostructured ferritic alloys' (NFAs)) are candidates for both the fuel cladding material of sodium-cooled fast reactors and structural materials for nuclear fusion power stations [13], as they have shown high radiation damage tolerance ( $>100$ displacements-per-atom (dpa)), high temperature mechanical strength $\left(600-800{ }^{\circ} \mathrm{C}\right)$ and high temperature creep resistance [14]. ODS steels contain a high density $\left(\sim 10^{23} \mathrm{~m}^{-3}\right)$ of yttrium-titanium-oxygen (Y-Ti-O) nano-oxides, typically sized $<2 \mathrm{~nm}$ in radius, which improve the high temperature strength and creep resistance of ferritic steels [15]. These Y-Ti-O nano-oxides have the added benefit of reducing the mean-free path of irradiation induced lattice defects (interstitial and vacancy clusters and point defects). Thus, they are also effective sinks for such defects to recombine [13]. Furthermore, the nano-oxides are sources of grain refinement due to the pinning of grain boundaries during heat treatment, which further increases the sink density. This combination of nano-oxides and fine grain structure are the source of ODS steels' exceptional tolerance to radiation damage.

During ODS steel powder consolidation, the mechanisms controlling microstructural evolution throughout recrystallisation are not well understood [16]. A bimodal grain structure after heat treatment and recrystallisation are a typical defining feature of ODS steels, comprising two distinctive regions of nanosized and microsized grains [17]. There are some reports of ODS steels with a "homogeneous" nanograin structure [18]; however, the majority of studies acknowledge grain size bimodality even for alloys with relatively high mechanical or radiation resistance performance. Previous studies [17,19] have investigated the bimodal grain size distributions in Fe-14Cr (wt. \%) ODS steels by using Electron Backscatter Diffraction (EBSD), Transmission Kikuchi Diffraction (TKD), nanoindentation and Atom Probe Tomography (APT). Short powder milling times have been found to increase the heterogeneity of the Y-Ti$\mathrm{O}$ particle size distribution, which is thought to increase the bimodality of the final grain structure [16]. García-Junceda et al. [17] found that $\mathrm{ZrO}_{2}$ added to Fe-14Cr-5Al-3W-0.4Ti$0.25 \mathrm{Y}_{2} \mathrm{O}_{3}$ (wt. \%) acted to refine the bimodal grain structure.

Consequently, understanding and control of grain size bimodality, heterogeneity of the grain sizes and Y-Ti-O nanocluster densities are likely important characteristics to control in the manufacture of ODS steels. Heintze et al. [20] showed that while hardening in ODS steels during self-ion irradiation was a function of grain size, the hardening during dual self-ion and helium-ion irradiation was a function of both the grain size and the Y-Ti-O particle density. This suggested that the tolerance of ODS steels to transmutation gases (hydrogen and helium) during neutron irradiation may be strongly dependent on the Y-Ti-O nanocluster density, and thus any large spatial variations in the particle density could lead to variations in these unique properties.

How the heterogeneity of Y-Ti-O nanoclusters and grain sizes influence the deformation micromechanics is also poorly understood, although a bimodality in microscale mechanical properties $[16,20]$ is thought to be related to the bimodality of the grain-sizes and Y-Ti-O particle distribution. Critically, it is this bimodality of mechanical properties that challenges the predictability of ODS steels performance as a fuel cladding material in sodium-cooled fast 
reactors and its use as a structural material for nuclear fusion reactors. A detailed characterisation to understand how these Y-Ti-O particles influence the deformation and mechanical properties would provide an insight into predicting the properties of this unique branch of steels.

In this study, a Fe- $14 \mathrm{Cr}-3 \mathrm{~W}-0.2 \mathrm{Ti}-0.25 \mathrm{Y}_{2} \mathrm{O}_{3}$ (nominal wt. \%) ODS steel (referred hereafter as 14YWT), typical in the field, was produced using the powder milling followed by hot isostatic pressing (HIP) consolidation. This batch of material has been studied before by Gorley [19] and Burrows [21], which provides useful additional data. Here, APT, EBSD, and transmission electron microscopy (TEM) were used to characterise the local nanoindentation deformation and its correlation with the microstructural features observed at room temperature. Even though the operational temperature of ODS steels are at high temperatures for nuclear systems, room temperature $\left(21{ }^{\circ} \mathrm{C}\right)$ mechanical properties should not be disregarded. The steel would be exposed to room temperatures during transport, storage and decommissioning. Thus, the mechanical properties at room temperature could provide a better understanding into the handling of these materials. The study was restricted to room temperature and unirradiated conditions to focus on the microstructure characterisation of deformation in ODS steels. Another focus of this study was to demonstrate the use of three techniques (APT, electron microscopy and nanoindentaion) and show how they are complementary with each other when used to characterise the microstructure of nanostructured materials.

\section{EXPERIMENTAL METHOD}

\subsection{ODS STEEL MANUFACTURING}

Given the difficulty of dispersing fine-scale oxides in liquid alloys and the preference for oxides $<5 \mathrm{~nm}$ diameter that can only be realised by in-situ precipitation, mechanical milling of pre-alloyed powders and $\mathrm{Y}_{2} \mathrm{O}_{3}$ followed by powder consolidation under vacuum and then heat treatment has emerged as the standard, preferred route to ODS steels. The ODS steel used here was milled in the Department of Materials, University of Oxford, and then HIP consolidated at the University of Birmingham, UK [19,21].

14YWT was produced by mechanically alloying of gas-atomised $\mathrm{Fe}-14 \mathrm{Cr}-3 \mathrm{~W}-0.2 \mathrm{Ti}$ (wt. \%) powder with $0.25 \mathrm{Y}_{2} \mathrm{O}_{3}$ (wt. \%) powder using AISI 52-100 steel (low Ni) pots and stainless steel balls at $250 \mathrm{rpm}$ in an Ar atmosphere for 60 hours with a ball-to-powder ratio of 10:1 and a ball diameter of $10 \mathrm{~mm}$. The milled powder was then degassed and packed into a mild steel can evacuated, sealed and HIPed at $150 \mathrm{MPa}$ and $1150^{\circ} \mathrm{C}$ for 4 hours [19]. The chemical composition of 14YWT is listed in Table 1. A slice of the consolidated alloy was cut from the can that had undergone the HIP technique using a diamond saw and then polished to a colloidal silica finish for microscopy, nanoindentation and focused ion beam (FIB) lift out for TEM and APT.

For comparison to $14 \mathrm{YWT}$, a pure nanocrystalline iron $(\mathrm{Fe})$ was produced by high-pressure torsion to provide the nanocrystalline grain structure as a baseline. This nanocrystalline iron material was used as a reference for grain boundary attribution to nanohardness measurements. 
Table 1: Bulk composition of 14YWT measured by X-ray fluorescence and LECO analysis (London \& Scandinavian Metallurgical Co Limited) and APT measurement.

\begin{tabular}{|l|c|c|c|}
\hline Element & Bulk (wt\%) & Bulk (at\%) & APT (at\%) \\
\hline $\mathrm{Cr}$ & 13.34 & 14.21 & $14.686 \pm 0.402$ \\
\hline $\mathrm{W}$ & 2.66 & 0.80 & $0.592 \pm 0.054$ \\
\hline $\mathrm{Ti}$ & 0.21 & 0.24 & $0.186 \pm 0.010$ \\
\hline $\mathrm{Y}_{2} \mathrm{O}_{3}$ & 0.30 & 0.05 & - \\
\hline $\mathrm{Al}$ & 0.11 & 0.23 & - \\
\hline $\mathrm{Mn}$ & 0.33 & 0.34 & $0.279 \pm 0.010$ \\
\hline $\mathrm{Si}$ & 0.18 & 0.36 & $0.404 \pm 0.018$ \\
\hline $\mathrm{C}$ & 0.09 & 0.42 & $0.016 \pm 0.001$ \\
\hline $\mathrm{N}$ & - & - & $0.063 \pm 0.012$ \\
\hline $\mathrm{Fe}$ & Bal. & Bal. & Bal. \\
\hline
\end{tabular}

\subsection{CHARACTERISATION TECHNIQUES}

EBSD was used on both the nanocrystalline Fe and 14YWT materials to determine the grain size distributions. A Zeiss Crossbeam 540 FIB/SEM and an Oxford Instruments EBSD detector were used to measure the diffraction patterns. Reconstruction of the maps was conducted using Oxford Instrument's Aztec version 3.3 SP1 and HKL Channel 5 version 5.12.67.0 software.

An Agilent G200 nanoindentor was used to measure hardness and modulus of the material by indenting a colloidal-silica polished surface to a $250 \mathrm{~nm}$ indentation depth at room temperature $\left(21^{\circ} \mathrm{C}\right)$. A continuous stiffness measurement system with a $2 \mathrm{~nm} 39 \mathrm{~Hz}$ harmonic displacement was used to measure the modulus and hardness as a function of indentation depth. A Berkovich tip was used and the tip area coefficients were calculated from the average load-displacement data of sixteen $2 \mu \mathrm{m}$ indents into fused silica. Thus, using the known area function and contact stiffness as a function of tip displacement, both the modulus and hardness of 14YWT and pure nanocrystalline $\mathrm{Fe}$ were calculated as a function of tip displacement.

Atom probe analysis was conducted with a CAMECA LEAP® ${ }^{2000 X R}$ at the Department of Materials, University of Oxford. Atom probe specimens were prepared by the lift-out technique [22] using a Zeiss NVision 40 FIB Scanning Electron Microscope (SEM). Cleaning of the specimens was performed using $2 \mathrm{kV}$ Ga ions to minimise FIB-induced damage. All atom probe specimens had tip diameters that were approximately between 50-100 nm.

The atom probe tips were cooled down to $50 \mathrm{~K}$. A $355 \mathrm{~nm}$ wavelength, frequency tripled $\mathrm{Nd}$ :YAG laser at $40 \mathrm{pJ}$ and $200 \mathrm{kHz}$ was used to sputter atoms from the tip under ultra-high vacuum, at an average detection rate of $0.5 \%$. The detection efficiency of the LEAP 5000XR is $52 \%$ [23]. CAMECA IVAS ${ }^{\circledR} 3.8 .2$ software was used to reconstruct the $3 \mathrm{D}$ chemical atomic maps. Reconstruction of all the atom probe data sets utilised the SEM tip profiles and pole indexing techniques. A maximum separation method [24] cluster algorithm was used on all APT datasets to determine the density, radius and composition of Y-Ti-O particles. Solute ions (TiO, $\mathrm{Y}$ and $\mathrm{YO}_{2}$ (YO was not detected within the datasets)) were selected for all the particle 
searches. The average APT compositional measurement across seven datasets is provided in Table 1.

TEM was conducted using a Jeol $2100 \mathrm{~L}$ with a $\mathrm{LaB}_{6}$ electron source and $200 \mathrm{kV}$ accelerating voltage. Scanning TEM (STEM) and Electron Dispersive X-Ray Spectroscopy (EDX) were conducted on a Jeol ARM200F with a cold field-emission gun source and $200 \mathrm{kV}$ accelerating voltage, and a $100 \mathrm{~mm}^{2}$ Centurion EDX detector. A Zeiss Auriga dual-beam FIB microscope was used to produce a single cross-section foil through two indents using the lift-out method [25]. Cleaning of the tips was performed on all samples using $2 \mathrm{kV} \mathrm{Ga}$ ions to minimise FIBinduced damage.

To image the dislocation network beneath the indents, conventional TEM (C-TEM) kinematical two-beam conditions, and zone-axis bright-field STEM techniques were used. CTEM is less practicable for imaging dislocations in highly deformed foils since the distortions in the lattice can significantly reduce the contrast from the localised strain fields of dislocations. In STEM, such distortions have much less effect on the contrast of dislocations due to the highly converged probe typically used [26]. STEM also significantly reduces the elastic contrast in the background by smearing out thickness-dependent contrast [27], allowing for improved contrast of dislocation networks over wide areas of deformed foils.

Porosity is a concern in the production of ODS steels [19]; this is problematic for TEM analysis since light particles (such as Y) show up with similar contrast to micro-pores in both C-TEM and STEM. Thus, chemical analysis is often necessary for distinguishing nanoscale oxides from cavities. High angle annular dark-field was therefore used alongside EDX mapping in order to confirm oxide particles from various parts of the microstructure and across a wide range of scales. Hyperspy [28] was used to extract qualitative element maps from the EDX spectrum images.

\section{RESULTS}

The grain structure from the EBDS analysis of the pure nanocrystalline iron material is shown in Figure 1. The average grain size was $150 \pm 50 \mathrm{~nm}$ with an average nanohardness of $7.5 \pm 0.3$ $\mathrm{GPa}$ and modulus of $245 \pm 10 \mathrm{GPa}$. The average hardness and modulus were determined from 16 indents at a $1000 \mathrm{~nm}$ depth.

One hundred $250 \mathrm{~nm}$ indents were made in 14YWT, arranged in a 10 by 10 grid with $15 \mu \mathrm{m}$ between each indent. The hardness and modulus values were determined between 125 to 225 $\mathrm{nm}$ from the load-displacement curve, as shown in Figure 2. The average hardness and modulus were found to be $5.8 \pm 1.1 \mathrm{GPa}$ and $239 \pm 12 \mathrm{GPa}$, respectively. An EBSD map was produced after the indentation to determine the crystallographic directions and grain sizes of the grain structure, which had a bimodal grain distribution, as shown in Figure 3. The microstructure was fully ferritic. There were two distant grain size distributions: $0-1 \mu \mathrm{m}$ and $1-20 \mu \mathrm{m}$ grain diameter ranges with averages of $0.53 \pm 0.16 \mu \mathrm{m}$ and $2.60 \pm 1.8 \mu \mathrm{m}$, respectively. It should be noted that no indentation sized effect was observed with both the nanocrystalline and 14YWT materials, which allowed for the comparison between each dataset.

Four indents in the 14YWT labelled A, B, C and D are highlighted in Figure 3 (b), with their corresponding hardness values; the indents were chosen based on their range of hardness 
values, showing a range of values, and lack of obvious grain boundary strengthening from local nanocrystalline grains, minimising the Hall-Petch effect. APT sample tips were taken underneath each identified indent to determine the nano-oxide distribution within the plastic zone produced by the nanoindentation. APT tips were made from the left, centre and right side of each indent, where sufficient data was collected. Indent A's APT Y and TiO atom maps are reconstructed, along with a 2.0 at $\%$ tungsten isosurface to highlight the grain boundary, as shown in Figure 4. Further, a proximity histogram [29] was calculated across this isoconcentration surface and shows the enrichment of tungsten at the grain boundary, as seen in Figure 5.

For all four indents listed in Figure 3-b), the density and average size of the nano-oxides were calculated using the method outlined in Section 2.2 and the results listed in Table 2. The Y-Ti$\mathrm{O}$ dispersion within each indent investigated was calculated by the maximum separation method cluster algorithm. The density and average size have been calculated using the IVAS software implementation of the algorithm. Solute ions, TiO, Y, and $\mathrm{YO}_{2}$, were selected for the algorithm. The optimal maximum separation parameterisation for cluster analysis was found for all APT datasets to be: $\mathrm{d}_{\max }=1.0 \mathrm{~nm}, \mathrm{~N}_{\min }=20, \mathrm{~L}=0.45 \mathrm{~nm}, \mathrm{D}_{\text {erosion }}=0.45 \mathrm{~nm}$, and $\mathrm{k}^{\text {th }}$ nearest neighbour order of 1 . Values that are missing in Table 2 were due to the atom probe tip fracturing before any significant amount of data could be collected.

Two further indents in 14YWT, labelled E and F, were chosen for TEM analysis based on their wide differences in hardness (similar to that seen in indents A-D), despite the lack of obvious differences in local surface grain boundary morphology. These indents are highlighted in Figure 3 (c), along with their corresponding hardness values. TEM was used to examine the material beneath indents $\mathrm{E}$ and $\mathrm{F}$ in order to assess the mechanisms behind the differences in hardness. Figure 6 shows a low magnification C-TEM image of each indent.

The plastic zone of indent $\mathrm{E}$ is clearly shown in Figure 7-b), extending approximately $1.5 \mu \mathrm{m}$ below the deepest point of the indent. Many dislocations were pinned against small defects in the matrix, presumably oxide particles; an example of such a dislocation is shown in Figure 7d). HAADF revealed that the larger grain beneath the indent contained an abrupt change in the visible density of oxide nanoclusters (the dark spots) midway through this large grain, as shown in Figure 7-a). There was also a pile-up of dislocations at this particle interface, which did not coincide with any grain boundary, in Figure 7-b).

HAADF was used to image the region immediately beneath the tip of indent $\mathrm{E}$, as shown in Figure $8-a, b)$. These were dark spots concentrated on one side of a small grain. The inset corresponding to Figure 8-c (EDX maps) indicate that the dark spots are yttrium oxide (likely close to $\mathrm{Y}_{2} \mathrm{O}_{3}$ ), as expected, but with a Ti-rich shell. It should be noted that titanium-rich shells were not found in the atom probe data. The grain boundary was comparatively enriched with $\mathrm{Cr}$ and $\mathrm{W} ; \mathrm{Al}$ and $\mathrm{Mn}$ were also weakly present and assumed contamination through the various stages of powder handling in production. No cavities were found under indent $\mathrm{E}$, which was verified by detecting yttrium within the EDX scans.

The plastic zone of indent $\mathrm{F}$ is clearly shown in Figure 9-a). Dislocations were more artificially extended longer than those in Figure 7-b) and Figure 8-b) since the foil was orientated close to a $\{110\}$ plane, on which two variants of the $\langle 111\rangle$-type screw dislocations would lie. HAADF 
again revealed a fine distribution of dark spots near the tip of the indent. Due to their small size, EDX maps were only acquired from single clusters here as shown in Figure 9-c).

HAADF was used to image the region immediately beneath the tip of indent $F$, as also shown in Figure 10-a,b). HAADF and EDX were used to examine if the Y-Ti-O distributions were different in the nanograins and larger grains. It has been shown through the HAADF micrographs in Figure 10-a,b) that large ODS particles were contained within nanograined regions. Since the largest ODS particles were generally found on or near grain boundaries, it could be inferred that the nano-grains should have a higher fraction of the large ODS particles since the grain boundaries are in closer proximity to each other. No cavities were found under indent $\mathrm{F}$, and this was verified by detecting yttrium within the EDX scans.

STEM-based estimates of the Y-Ti-O density for those regions that were qualitatively homogeneous within large grains ranged from $\sim 7 \times 10^{22} \mathrm{~m}^{-3}$ (measured from the centre of a large grain beneath indent E) to $\sim 1 \times 10^{23} \mathrm{~m}^{-3}$ (measured immediately beneath indent F). For both these measurements, the particles diameters were $3 \pm 1 \mathrm{~nm}$. In the nanograined regions, the Y-Ti-O nanoparticle density was calculated as $\sim 5 \times 10^{22} \mathrm{~m}^{-3}$, with larger diameters of $7 \pm 2 \mathrm{~nm}$.

The Y-Ti-O number density measurements from APT (at near atomic resolution) were generally much larger than those obtained by STEM, which may indicate that HAADF did not resolve the smallest Y-Ti-O clusters, and this reflects the difficulty in quantifying a high density of $\sim 1 \mathrm{~nm}$ sized clusters in a 2D projection of a TEM foil. The APT-based number density measurements were thus considered a more reliable estimate of the ODS particle density.

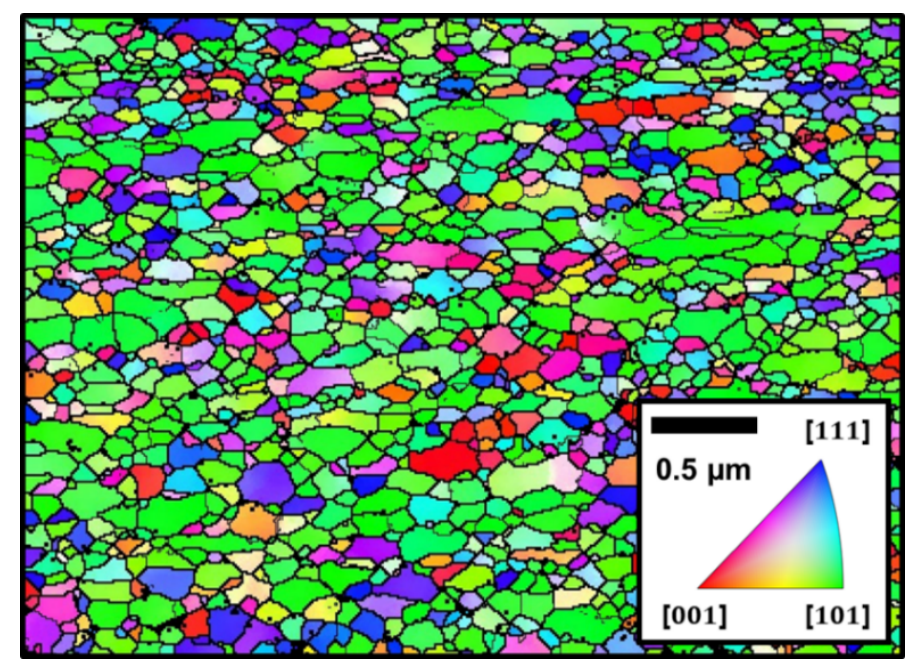

Figure 1: Microstructure of the nanocrystalline iron material using EBSD. An inverse pole key is shown for the crystallographic directions. 


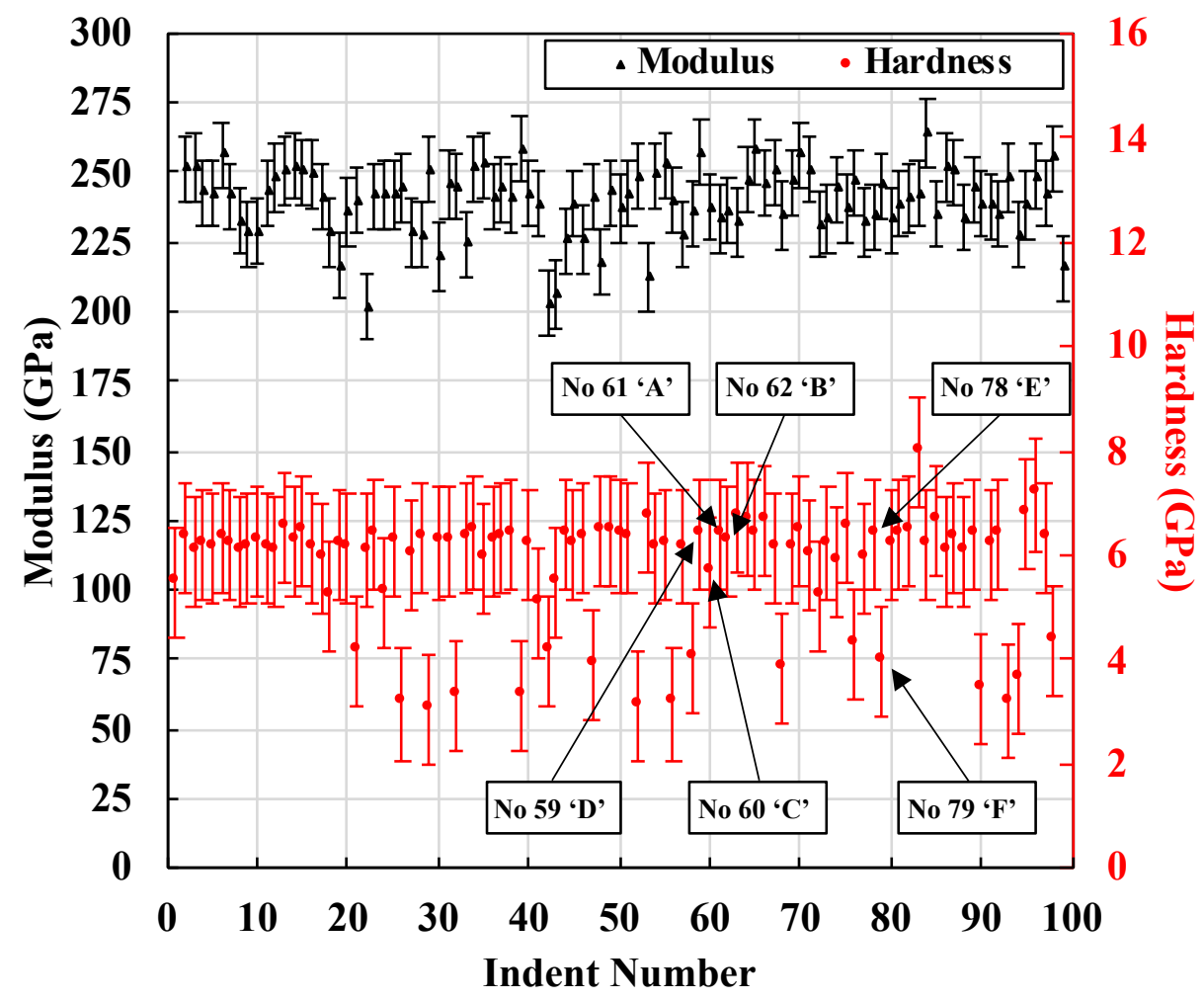

Figure 2: The hardness and modulus values of 14YWT for all the indents. The values were determined between 125 to $225 \mathrm{~nm}$ from the load-displacement curve. For reference, the nanocrystalline Fe's hardness and modulus were $7.5 \pm 0.3 \mathrm{GPa}$ and modulus of $245 \pm 10 \mathrm{GPa}$, respectively. 


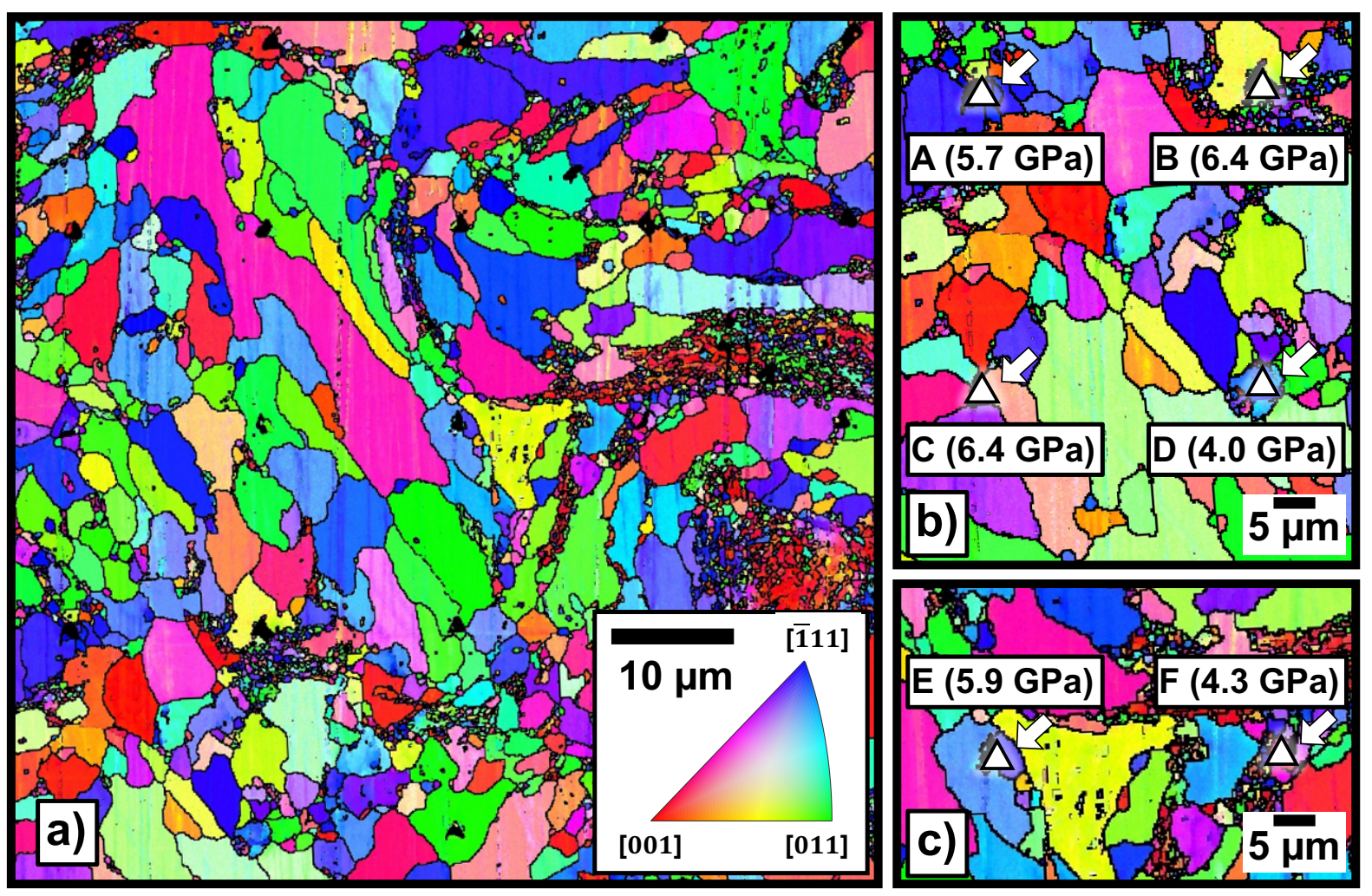

Figure 3: a) EBSD map section of the 100 indents showing a bimodal grain structure in 14YWT. b) Identification of the four A-D indents that were investigated with APT with their respective hardness values. (c) Identification of indents $E$ and $F$ lifted out for TEM analysis with their respective hardness values. The indents of interest are highlighted triangles and arrows in b) and c). An inverse pole key is shown for the crystallographic directions. 

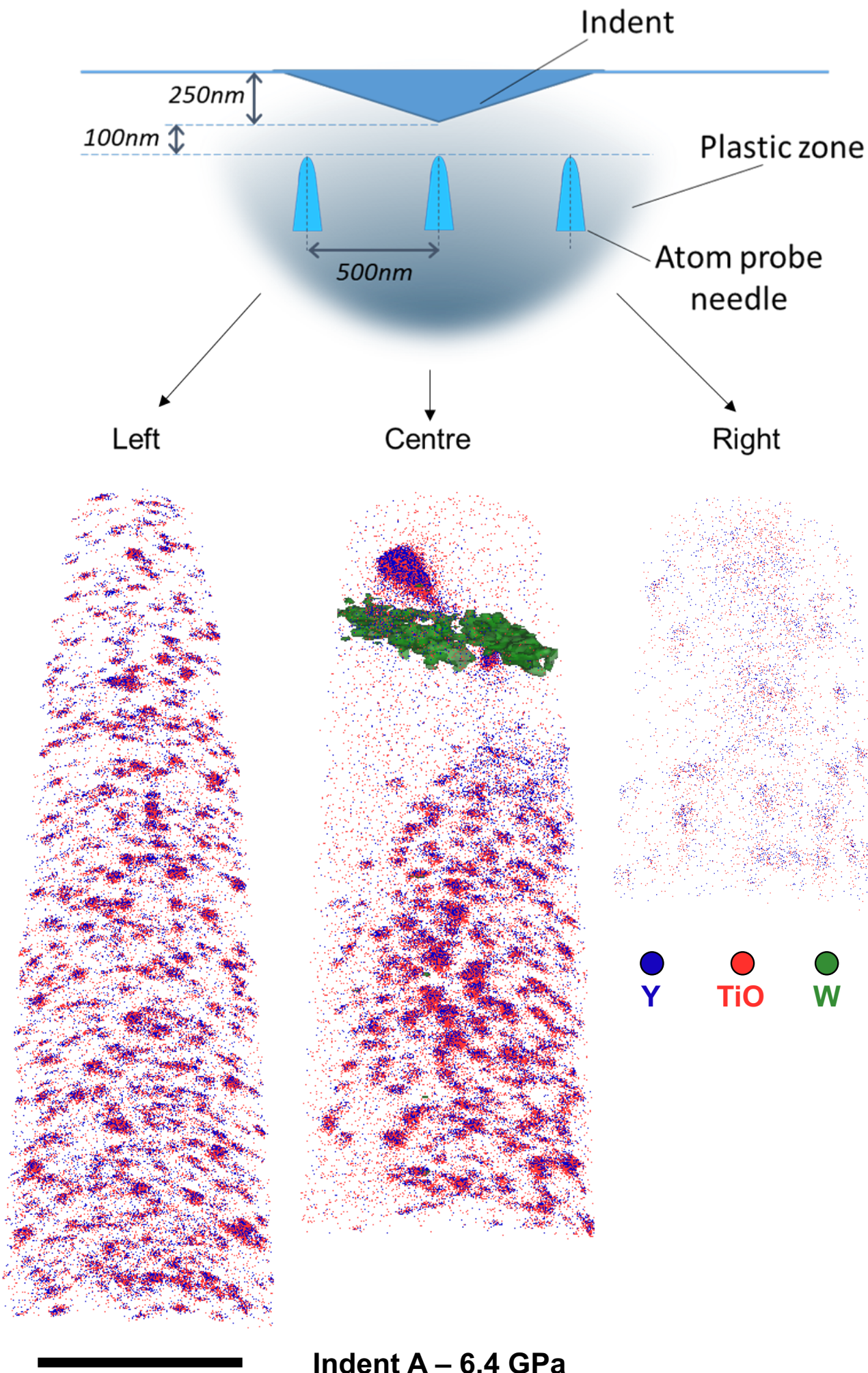

$50 \mathrm{~nm}$

Figure 4: APT reconstruction of the material underneath indent $\mathrm{A}$ in Figure 3-b). The distribution of $\mathrm{Y}, \mathrm{W}$ and $\mathrm{TiO}$ has been displayed for each tip (left, centre and right). A 2.0 at $\%$ isoconcentration surface of $\mathrm{W}$ for the centre tip has been displayed to demonstrate the 
enrichment of $\mathrm{W}$ at grain boundaries. The inhomogeneous distribution of $\mathrm{Y}$ and $\mathrm{TiO}$ can be seen in this case.

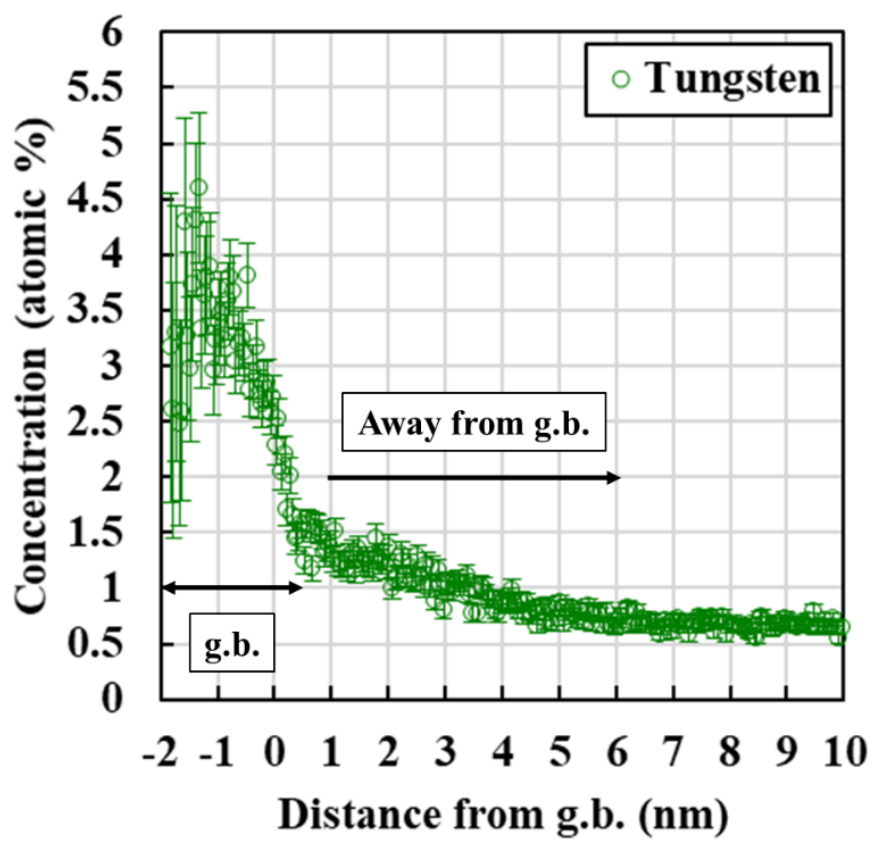

Figure 5: APT proxigram across the grain boundary (g.b.) with a 2.0 at $\% \mathrm{~W}$ isosurface shown in Figure 4.

Table 2: Summary of hardness values in indents A, B, C and D in Fig 3-b) and nanocluster analysis from APT of the plastic zone volumes beneath each indent. Vacant data indicates that the atom probe tip fractured before sufficient data was acquired.

\begin{tabular}{cccccccc} 
& & \multicolumn{2}{c}{ Number Density of Y-Ti-O $\left(\# / \mathrm{m}^{3}\right)$} & \multicolumn{3}{c}{ Guinier radius of Y-Ti-O (nm) } \\
\hline \hline \multirow{2}{*}{ Indent } & $\begin{array}{c}\text { Hardness } \\
(\mathrm{GPa})\end{array}$ & \multirow{2}{*}{ Left Tip } & Centre Tip & Right Tip & $\begin{array}{c}\text { Left } \\
\text { Tip }\end{array}$ & $\begin{array}{c}\text { Centre } \\
\text { Tip }\end{array}$ & Right Tip \\
\hline \hline A & $5.7 \pm 0.2$ & $(1.5 \pm 0.1) \times 10^{24}$ & $(7.2 \pm 0.1) \times 10^{23}$ & $(1.2 \pm 0.1) \times 10^{24}$ & $2.0 \pm 0.2$ & $2.2 \pm 0.3$ & $2.0 \pm 0.2$ \\
B & $6.4 \pm 0.1$ & $(4.7 \pm 0.1) \times 10^{23}$ & - & $(2.1 \pm 0.2) \times 10^{23}$ & $1.0 \pm 0.2$ & - & $2.6 \pm 0.2$ \\
C & $6.4 \pm 0.1$ & $(1.6 \pm 0.1) \times 10^{24}$ & $(1.2 \pm 0.1) \times 10^{24}$ & $(1.2 \pm 0.1) \times 10^{24}$ & $1.9 \pm 0.2$ & $2.1 \pm 0.2$ & $2.3 \pm 0.2$ \\
D & $4.0 \pm 0.1$ & - & - & $(1.7 \pm 0.1) \times 10^{24}$ & - & - & $2.0 \pm 0.2$ \\
\hline \hline
\end{tabular}



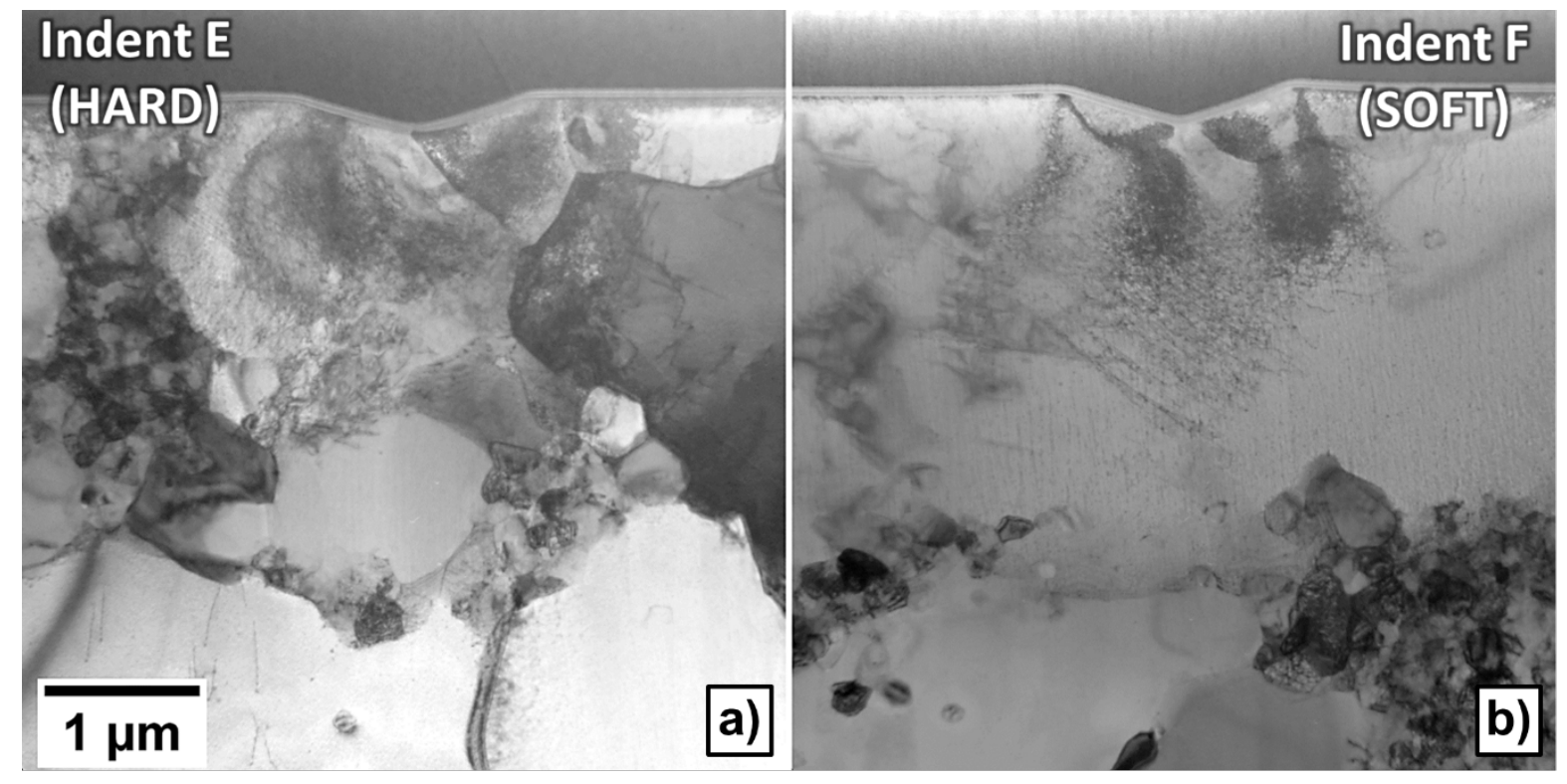

Figure 6: Bright field TEM micrographs of cross-sections taken from indents a) E (hard) and b) F (soft) in Fig 3-c).

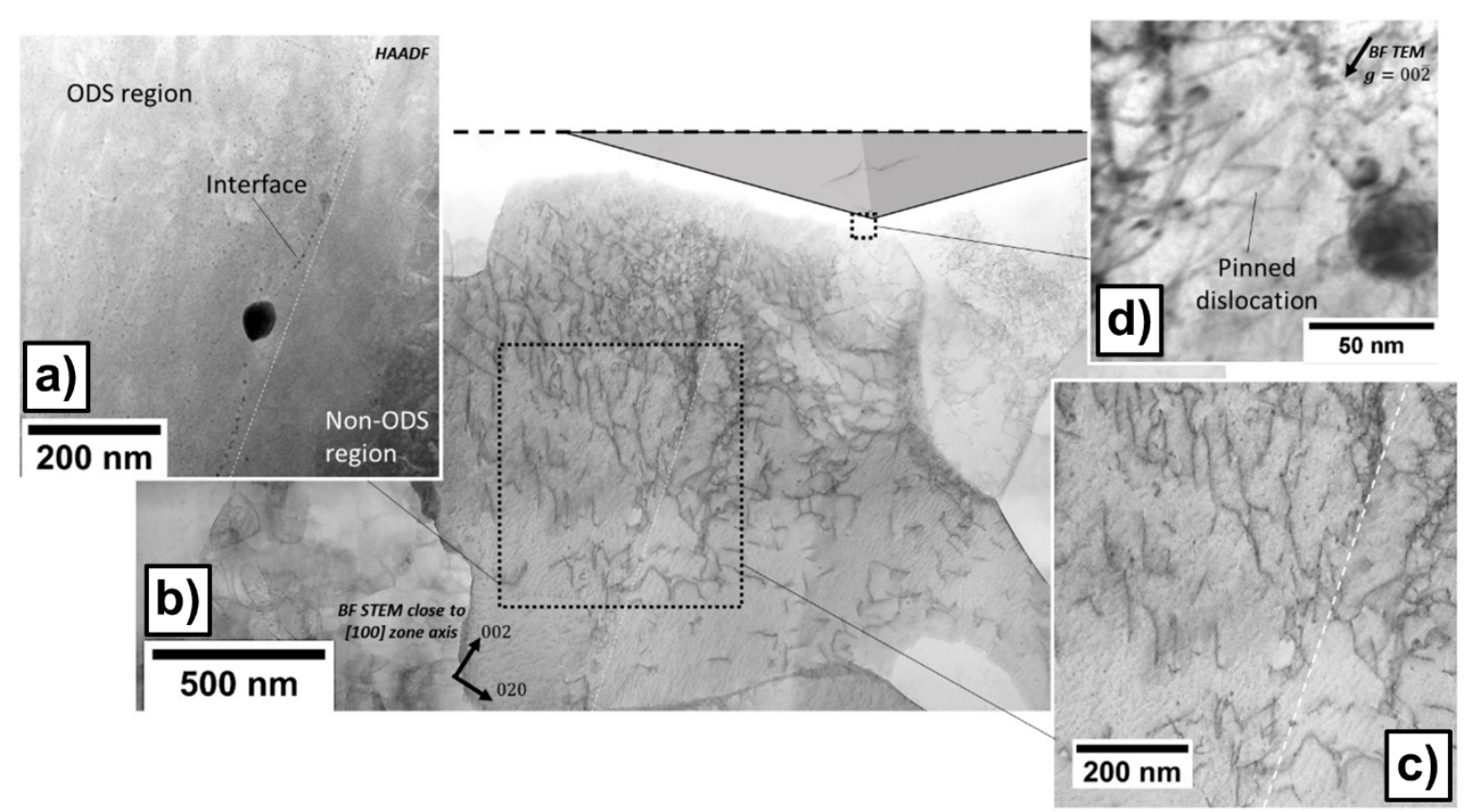

Figure 7: TEM and STEM micrographs of a dislocation network beneath indent E (hard). a) The HAADF image shows an abrupt change in oxide particle density in the region indicated (labelled ODS and non-ODS regions); b) the BF STEM shows a pile up of dislocations at this interface. c) A white dashed line indicates this interface. d) A typical example of a pinned dislocation is also shown. 


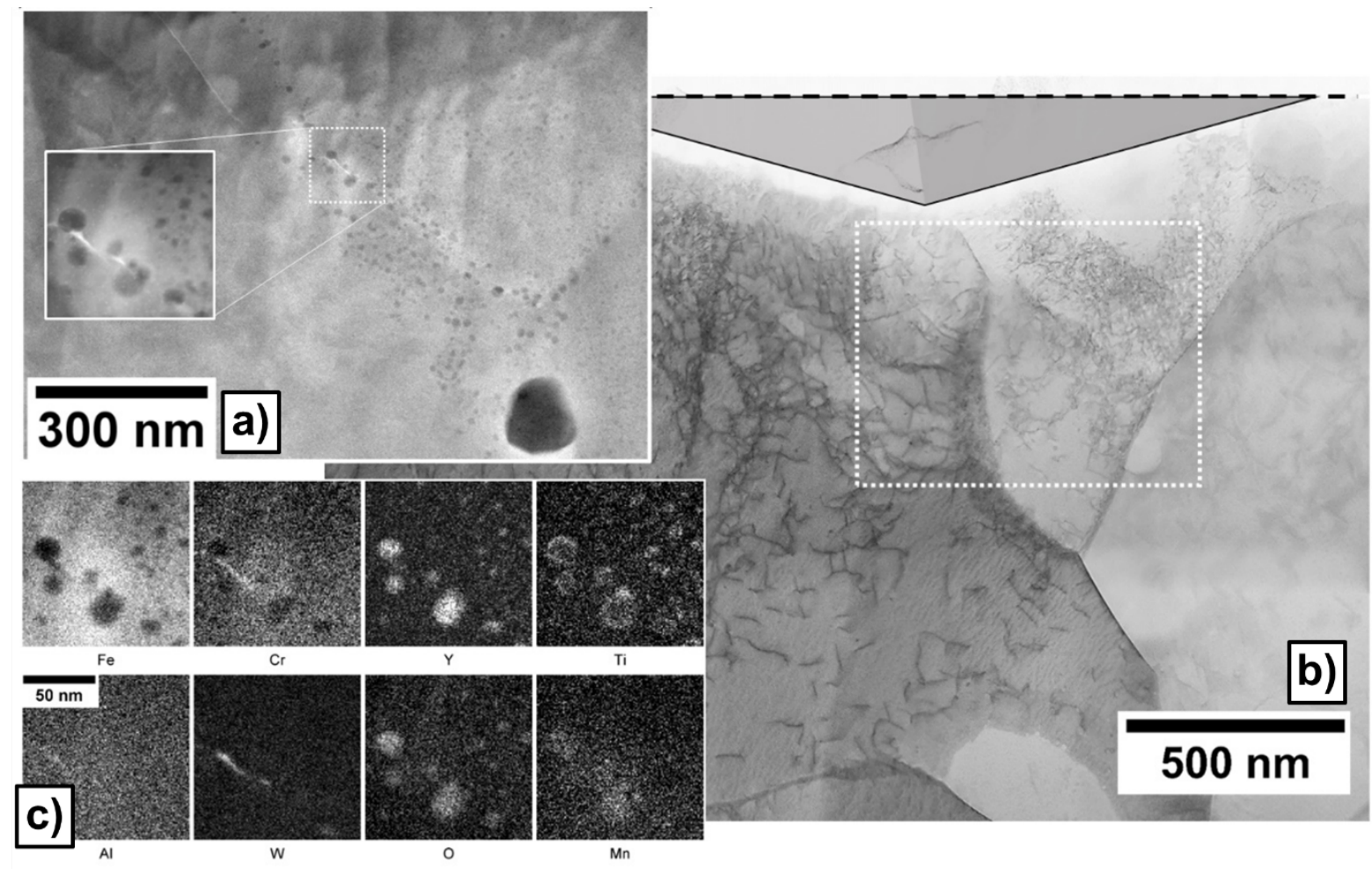

Figure 8: a)-b) STEM micrographs and c) qualitative EDX element maps (L- $\alpha$ lines) from a region immediately beneath the tip of indent $\mathrm{E}$ (hard).

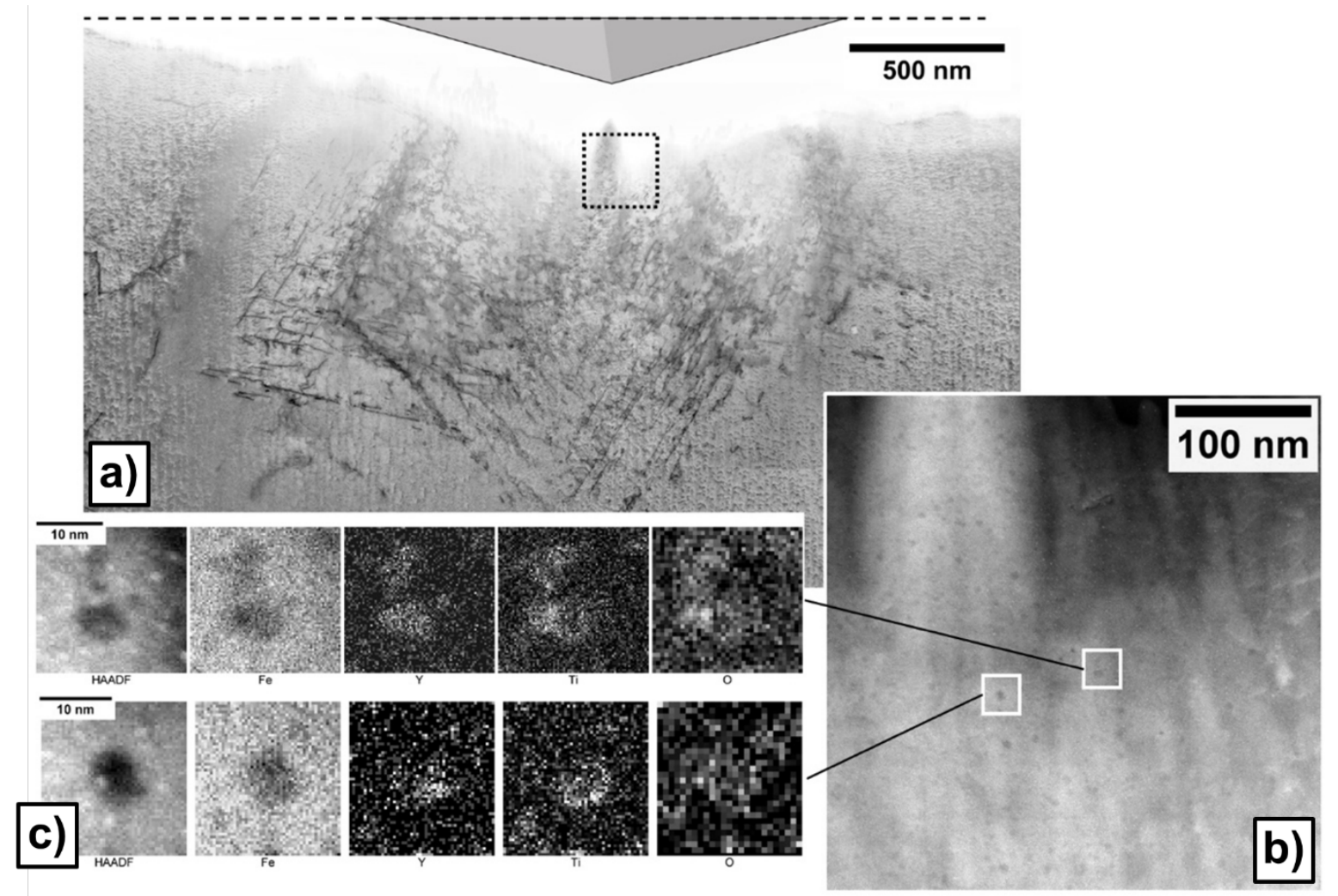


Figure 9: a)-b) STEM micrographs and c) qualitative EDX element maps (L- $\alpha$ lines) from a region immediately beneath the tip of indent $\mathrm{F}$ (soft). Note: The white dots visible in the HAADF images besides the EDX maps are carbon contaminants on the foil surface and are unrelated to the microstructure.

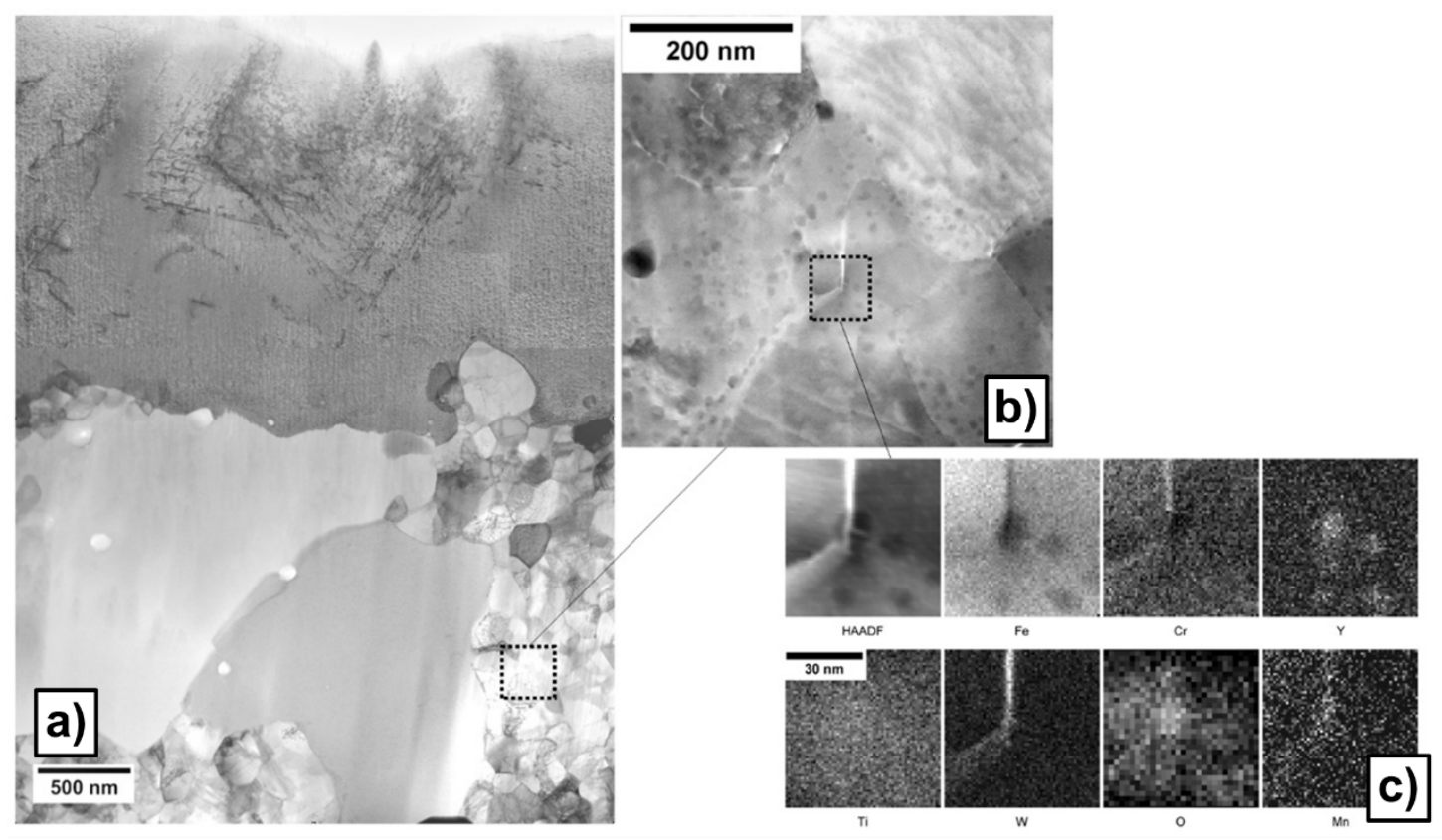

Figure 10: a)-b) STEM micrographs and c) qualitative EDX element maps (L- $\alpha$ lines) from a nanograin region beneath the plastic zone of indent $\mathrm{F}$ (soft).

\section{DISCUSSION}

One must consider various facets in order to rationalize how the Y-Ti-O particles influences the deformation mechanisms in and around the nanoindents. The 14YWT hardness showed a bimodal distribution, and this might simply relate to the spatial heterogeneity in Y-Ti-O particle number density i.e. if the nano-oxide dispersion is non-uniform, then the associated dispersion hardening will also be non-uniform [30,31]. However, the hardness values of indents $\mathrm{B}$ and $\mathrm{C}$ were both $6.4 \pm 0.1 \mathrm{GPa}$, despite different APT number densities of Y-Ti-O particles of $5.8 \pm 0.1 \times 10^{23} \mathrm{~m}^{-3}$ and $1.3 \pm 0.1 \times 10^{24} \mathrm{~m}^{-3}$, respectively (taking an average of left, centre and right APT tips). Further, the Guinier radius was $1.8 \pm 0.2 \mathrm{~nm}$ and $2.1 \pm 0.2 \mathrm{~nm}$ respectively (again taking an average of the left, centre and right tips). In contrast, indent D had a hardness of $4.0 \pm 0.1 \mathrm{GPa}$ and a number density of Y-Ti-O particles of $1.7 \times 10^{24} \mathrm{~m}^{-3}$. In other words, even though the hardness increased from $4.0 \pm 0.1 \mathrm{GPa}$ (indent D) to $6.4 \pm 0.1 \mathrm{GPa}$ (indent C), the $\mathrm{Y}$ Ti-O particle number density remained near-constant and equal to $1.7 \pm 0.2 \times 10^{24} \mathrm{~m}^{-3}$. Thus, the dominant hardening mechanisms was not $\mathrm{Y}-\mathrm{Ti}-\mathrm{O}$ based dispersion hardening.

14YWT had an average hardness and modulus of $5.8 \pm 1.1 \mathrm{GPa}$ and $239 \pm 12 \mathrm{GPa}$, respectively, with two distant grain size distributions of $0-1 \mu \mathrm{m}$ and $1-20 \mu \mathrm{m}$ grain diameter ranges with an average of $0.53 \pm 0.16 \mu \mathrm{m}$ and $2.60 \pm 1.8 \mu \mathrm{m}$, respectively. For comparison, the nanocrystalline iron had a hardness on average $7.5 \pm 0.3 \mathrm{GPa}$, and modulus of $245 \pm 10 \mathrm{GPa}$ with an average grain size of $150 \pm 50 \mathrm{~nm}$ 
The TEM analysis showed that the plastic zone extended to $\sim 2 \mu \mathrm{m}$ below each indent $(\sim 8$ times the indenter depth of $250 \mathrm{~nm}$ ). The plastic zone beneath indent $\mathrm{F}$ (the softer of the two indents) was mostly contained within a single grain, except for a small grain at the surface, allowing dislocations to propagate unconstrained through the grain. The microstructure beneath indent $\mathrm{E}$ (the harder indent) was mostly polycrystalline. The plastic zone extended to a nano-grained region on the left-hand side of the indent, and beyond the grain-boundaries between the larger grains on the right-hand side and below the indent. Evidently in this case, the dislocations were more constrained by the grain boundaries.

The grain structure alone can be suggested as the pre-dominant hardening mechanism, however the role of ODS particles on dislocations must be considered. These nano-oxides were captured in conventional two-beam bright field conditions, and in zone-axis bright field STEM. HAADF, complemented by EDX maps, was also used to examine the oxide nanoclusters. Further thinning of the foils was conducted after capturing the images in Figure 6-a,b), which resulted in the loss of the protective platinum layer and some of the near-surface material, as is noticeable in subsequent micrographs.

The softer indent, indent F, examined by STEM appeared to contain a relatively homogeneous distribution of Y-Ti-O beneath the indent, as shown in Figure 9-b), whereas the harder indent E contained a more obviously heterogeneous distribution with large depletion zones absent of TEM-visible clusters, as shown in Figure $8-\mathrm{a}, \mathrm{b}$ ). This finding, alongside the APT results, implies that the majority of hardening is likely to arise from the grain refinement, rather than by dislocation pinning on the Y-Ti-O particles (as shown in Figure 7-d)).

Generally, the Y-Ti-O dispersion strengthening contribution has been explained, and quantified, by the Orowan by-pass mechanism with a key assumption that the particles are impenetrable. Shen et al. [32] performed such a calculation but did not provide evidence for this assumption to be reasonable. The dislocation TEM analysis within the plastic zone of a nanoindent within 14YWT, as shown by Figure 7, indicated that the dislocations were straight, rather than bowed around the Y-Ti-O particles; this implies that the Y-Ti-O were partially penetrable, not fully impenetrable. The evidence shown within this study demonstrate that the Y-Ti-O particles were partially penetrable at room temperature, which explains their minimal contribution to strengthening. It should be noted that the dispersion strengthening is also dependent on the inter-particle distance. However, the TEM analysis conducted within this study was unable to resolve particles less than $3 \mathrm{~nm}$ and the distances between Y-Ti-O ppts in the APT data would be subjected to reconstruction aberrations, thus potentially providing misleading results. The determination of the inter-particle spacing was not calculated within this paper. The investigation of the particle/matrix interface coherency was beyond the scope of this study (it has been investigated in previous literature [33]).

Another feature was the enrichment of $\mathrm{W}$ at grain boundaries, as shown in Figure 8-c) and Figure 10-c). This enrichment was confirmed by APT analysis of two grain boundaries in the datasets, with an average composition of $\sim 3.5$ at $\% \mathrm{~W}$, as shown in Figure 5Figure 4 . It should be noted that the bulk W in 14YWT was 0.80 at $\%$. W enrichment at the grain boundaries have been shown to provide some strengthening, indicating that W enrichment observed in 14YWT strengthen the grain boundaries (thus, this has shown to increase creep resistance) [34-36]. In 
addition, the combined STEM and APT analysis suggests that the Y-Ti-O dispersion was not uniform in general.

Overall, the major hardening mechanism was due to grain boundary refinement, rather than directly to the number density or homogeneity of Y-Ti-O particle distribution. This finding is consistent with the high hardness measurement of $7.5 \pm 0.25 \mathrm{GPa}$ for the pure nanocrystalline Fe with an average grain size of $150 \pm 50 \mathrm{~nm}$. There is no doubt that the high hardness in the nanocrystalline Fe is caused by the very fine grain structure. It is noted that another common feature of 14YWT grain boundaries was the larger Y-Ti-O particle densities close to the boundaries (see Figure 8 -a,c) and Figure 10-b,c)). It is not possible to separate the strengthening effects of these larger Y-Ti-O particles from the grain boundaries themselves in this study. Furthermore, model alloys and pure iron produced by high-pressure torsion can provide a suitable baseline for the effects of grain refinement.

It should be noted that the studies were conducted at room temperature. High temperature mechanical properties and their relation to the microstructure is vitally important for the use of these steels in high temperature application, such as fuel cladding in sodium-cooled fast reactors. However, the investigation of high temperature mechanical properties, and high temperature creep resistance, is beyond the scope of this study.

It has been common practice to compare 14YWT to 'non-ODS' variants, which have the same composition but no addition of $\mathrm{Y}_{2} \mathrm{O}_{3}$ powder [19,37]. Inevitably, the alloys have very different final ferritic grain structures because there is no grain refinement/pinning effect from the Y-Ti$\mathrm{O}$ particles during recrystallization. These studies then highlight differences in mechanical properties between the alloys; the results here suggest these differences, at least at room temperature, may be more due to the effect of grain refining than by direct effects of dispersion hardening.

\section{CONCLUSION}

In the development of new fuel cladding materials for sodium-cooled fast reactors and structural materials for nuclear fusion power reactors, 14YWT steel is regarded as promising candidate. In this study, 14YWT has been investigated by a combination of TEM and EBSD microscopy, APT and nanoindentation at room temperature to understand better the factors controlling its hardness, as a proxy measurement for its likely macro-scale mechanical properties. The findings were as follows:

1. The average number density and diameter of Y-Ti-O particles had a relatively small effect on the hardness, suggesting that the dominant hardening mechanism may relate more strongly to other microstructural features.

2. TEM imaging of the plastic zone beneath nano-indents suggested that the dominant strengthening mechanism was grain boundary hardening due to grain refinement, rather than dislocation pinning on the Y-Ti-O particles. This is consistent with the high hardness measurement of pure nanocrystalline Fe.

3. Grain boundaries were enriched with $\mathrm{W}$, which is also thought to improve the grain boundary strength.

4. As is typical for this alloy class, the distribution of Y-Ti-O particles was comparatively non-uniform, with number densities ranging from $10^{23}-10^{24} \mathrm{~m}^{-3}$. 
5. The Y-Ti-O particle diameter varied from region to region, with large (few microns to $10 \mathrm{~s}$ of microns) grains containing particles of $1-3 \mathrm{~nm}$, as well as nano-grained regions $(\sim 100 \mathrm{~nm})$ containing particles sized on typically $\sim 7 \mathrm{~nm}$, and up to $\sim 15 \mathrm{~nm}$.

6. Overall, the presence of nano-oxides, Y-Ti-O, may have an indirect effect on the hardness through the effect of grain refinement.

Overall the results suggest that for the alloy studied here in terms of hardening it is the grain boundary pinning effect of Y-Ti-O clusters (and associated grain refinement) during recrystallization that underpins the excellent yield strength of ODS alloys, and not direct dispersion strengthening effects, despite various types of microstructural inhomogeneity at the grain diameter and Y-Ti-O nanoparticle scale. The balance between grain boundary and dispersion strength will vary with temperature, and from alloy to alloy. Although nanoparticles/clusters may be less important in strengthening, they retain their importance in conferring radiation resistance. Furthermore, this study demonstrated how electron microscopy, APT and nanoindentaion techniques complement each other when characterising a material.

\section{ACKNOWLEDGEMENTS}

T. P. Davis is funded by the Clarendon Scholarship from the University of Oxford and Engineering and Physical Sciences Research Council Fusion Centre for Doctorial Training [EP/L01663X/1]. STEM was performed using 'South of England Analytical Electron Microscope' at the University of Oxford, supported by a UK Engineering and Physical Sciences Research Council (EPSRC) grant EP/K040375/1. This work was also supported by the Platform Grant 'Advanced Nuclear Materials' (EP/P001645/1) and supported by EPSRC via a Programme Grant "Materials for Fusion and Fission Power", EP/H018921. APT was supported by EPSRC grant EP/M022803/1 "A LEAP 5000XR for the UK National Atom Probe Facility."

\section{DATA AVAILABILITY}

Data obtained in this study is available online from https://doi.org/10.5287/bodleian:ORzBPwbE0

\section{REFERENCES}

[1] I. Pioro, Handbook of Generation IV Nuclear Reactors, Elsevier Science, 2016. https://books.google.co.uk/books?id=8JLBCQAAQBAJ.

[2] C. Andrieux, F. Baqué, B. Bonin, B. Boullis, C. Cabet, F. Carré, P. Dufour?, F. Gauché, J.-P. Grouiller, J.G. (Topic Editor), J.-P. Jeannot, C. Latgé, M. Le Flem, P. Le Coz, L. Martin, M. Masson, G. Mathonnière, J.-G. Nokhamzon, M. Pelletier, G. Rodriguez, M. Saez, J.-L. Séran, F. Varaine, A. Zaetta, Sodium-Cooled Nuclear Reactors Monograph, CEA, 2016. http://www.materials.cea.fr/en/PDF/Sodium-Cooled Nuclear Reactor_CEA-en.pdf.

[3] S.J. Zinkle, G.S. Was, Materials challenges in nuclear energy, Acta Mater. 61 (2013) 735-758. https://doi.org/10.1016/J.ACTAMAT.2012.11.004.

[4] F. Delage, J. Carmack, C.B. Lee, T. Mizuno, M. Pelletier, J. Somers, Status of advanced fuel candidates for Sodium Fast Reactor within the Generation IV 
International Forum, J. Nucl. Mater. 441 (2013) 515-519. https://doi.org/10.1016/j.jnucmat.2012.09.036.

[5] T.P. Davis, Review of the iron-based materials applicable for the fuel and core of future Sodium Fast Reactors (SFR), Off. Nucl. Regul. ONR-RRR-08 (2018) 1-52. http://www.onr.org.uk/documents/2018/onr-rrr-088.pdf.

[6] A. V. Tselishchev, V.S. Ageev, Y.P. Budanov, A.G. Ioltukhovskii, N.M. Mitrofanova, M. V. Leontieva-Smirnova, I.A. Shkabura, L.M. Zabud'Ko, A. V. Kozlov, V. V. Mal'Tsev, A. V. Povstyanko, Development of structural steel for fuel elements and fuel assemblies of sodium-cooled fast reactors, At. Energy. 108 (2010) 274-280. https://doi.org/10.1007/s10512-010-9289-9.

[7] F.A. Garner, M.B. Toloczko, B.H. Sencer, Comparison of swelling and irradiation creep behavior of fcc-austenitic and bcc-ferritic/martensitic alloys at high neutron exposure, J. Nucl. Mater. 276 (2000) 123-142. https://doi.org/10.1016/S00223115(99)00225-1.

[8] K.L. Murty, I. Charit, Structural materials for Gen-IV nuclear reactors: Challenges and opportunities, J. Nucl. Mater. 383 (2008) 189-195. https://doi.org/10.1016/j.jnucmat.2008.08.044.

[9] A.-A.. Tavassoli, J.-W. Rensman, M. Schirra, K. Shiba, Materials design data for reduced activation martensitic steel type F82H, Fusion Eng. Des. 61-62 (2002) 617628. https://doi.org/https://doi.org/10.1016/S0920-3796(02)00255-7.

[10] L. Tan, R.E. Stoller, K.G. Field, Y. Yang, H. Nam, D. Morgan, B.D. Wirth, M.N. Gussev, J.T. Busby, Microstructural Evolution of Type 304 and 316 Stainless Steels Under Neutron Irradiation at LWR Relevant Conditions, Jom. 68 (2016) 517-529. https://doi.org/10.1007/s11837-015-1753-5.

[11] A.A.F. Tavassoli, A. Alamo, L. Bedel, L. Forest, J.M. Gentzbittel, J.W. Rensman, E. Diegele, R. Lindau, M. Schirra, R. Schmitt, H.C. Schneider, C. Petersen, A.M. Lancha, P. Fernandez, G. Filacchioni, M.F. Maday, K. Mergia, N. Boukos, Baluc, P. Spätig, E. Alves, E. Lucon, Materials design data for reduced activation martensitic steel type EUROFER, J. Nucl. Mater. 329-333 (2004) 257-262.

https://doi.org/10.1016/j.jnucmat.2004.04.020.

[12] E. Gaganidze, F. Gillemot, I. Szenthe, M. Gorley, M. Rieth, E. Diegele, Development of EUROFER97 database and material property handbook, Fusion Eng. Des. 135 (2018) 9-14. https://doi.org/10.1016/j.fusengdes.2018.06.027.

[13] S.J. Zinkle, J.L. Boutard, D.T. Hoelzer, A. Kimura, R. Lindau, G.R. Odette, M. Rieth, L. Tan, H. Tanigawa, Development of next generation tempered and ODS reduced activation ferritic/martensitic steels for fusion energy applications, Nucl. Fusion. 57 (2017). https://doi.org/10.1088/1741-4326/57/9/092005.

[14] P. Dubuisson, Y. De Carlan, V. Garat, M. Blat, ODS Ferritic/martensitic alloys for Sodium Fast Reactor fuel pin cladding, J. Nucl. Mater. 428 (2012) 6-12. https://doi.org/10.1016/j.jnucmat.2011.10.037.

[15] G.R. Odette, On the status and prospects for nanostructured ferritic alloys for nuclear fission and fusion application with emphasis on the underlying science, Scr. Mater. 143 (2018) 142-148. https://doi.org/10.1016/j.scriptamat.2017.06.021.

[16] I. Hilger, F. Bergner, T. Weißgärber, Bimodal Grain Size Distribution of Nanostructured Ferritic ODS Fe-Cr Alloys, J. Am. Ceram. Soc. 98 (2015) 3576-3581. https://doi.org/10.1111/jace.13833.

[17] A. García-Junceda, M. Campos, N. García-Rodríguez, J.M. Torralba, On the Role of Alloy Composition and Sintering Parameters in the Bimodal Grain Size Distribution 
and Mechanical Properties of ODS Ferritic Steels, Metall. Mater. Trans. A Phys. Metall. Mater. Sci. 47 (2016) 5325-5333. https://doi.org/10.1007/s11661-016-3538-z.

[18] J.H. Kim, T.S. Byun, D.T. Hoelzer, Tensile fracture characteristics of nanostructured ferritic alloy 14YWT, J. Nucl. Mater. 407 (2010) 143-150. https://doi.org/10.1016/j.jnucmat.2010.09.054.

[19] M.J. Gorley, Powder processing of oxide dispersion strengthened alloys for nuclear applications, University of Oxford, 2014.

[20] C. Heintze, I. Hilger, F. Bergner, T. Weissgärber, B. Kieback, Nanoindentation of single- $(\mathrm{Fe})$ and dual-beam (Fe and $\mathrm{He})$ ion-irradiated ODS Fe-14Cr-based alloys: Effect of the initial microstructure on irradiation-induced hardening, J. Nucl. Mater. 518 (2019) 1-10. https://doi.org/10.1016/j.jnucmat.2019.02.037.

[21] C. Burrows, The irradiation resistance of oxide dispersion strengthened steels, University of Oxford, 2015.

[22] M.K. Miller, K.F. Russell, K. Thompson, R. Alvis, D.J. Larson, Review of Atom Probe FIB-Based Specimen Preparation Methods, Microsc. Microanal. 13 (2007) 428436. https://doi.org/10.1017/S1431927607070845.

[23] T.L. Martin, A.J. London, B. Jenkins, S.E. Hopkin, J.O. Douglas, P.D. Styman, P.A.J. Bagot, M.P. Moody, Comparing the Consistency of Atom Probe Tomography Measurements of Small-Scale Segregation and Clustering between the LEAP 3000 and LEAP 5000 Instruments, Microsc. Microanal. 23 (2017) 227-237. https://doi.org/10.1017/S1431927617000356.

[24] J.M. Hyde, C.A. English, Symposium R: Microstructural Processes in Irradiated Materials, in: MRS 2000 Fall Meet., 2000.

[25] L.A. Giannuzzi, J.L. Drown, S.R. Brown, R.B. Irwin, F.A. Stevie, Applications of the FIB lift-out technique for TEM specimen preparation, Microsc. Res. Tech. 41 (1998) 285-290. https://doi.org/10.1002/(SICI)1097-0029(19980515)41:4<285::AIDJEMT1>3.0.CO;2-Q.

[26] Y. Miyajima, M. Mitsuhara, S. Hata, H. Nakashima, N. Tsuji, Quantification of internal dislocation density using scanning transmission electron microscopy in ultrafine grained pure aluminium fabricated by severe plastic deformation, Mater. Sci. Eng. A. 528 (2010) 776-779. https://doi.org/https://doi.org/10.1016/j.msea.2010.09.058.

[27] C.M. Parish, K.G. Field, A.G. Certain, J.P. Wharry, Application of STEM characterization for investigating radiation effects in BCC Fe-based alloys, J. Mater. Res. 30 (2015) 1275-1289. https://doi.org/10.1557/jmr.2015.32.

[28] F. de la Peña, T. Ostasevicius, V.T. Fauske, P. Burdet, E. Prestat, P. Jokubauskas, M. Nord, K.E. MacArthur, M. Sarahan, D.N. Johnstone, J. Taillon, A. Eljarrat, V. Migunov, J. Caron, T. Furnival, S. Mazzucco, T. Aarholt, M. Walls, T. Slater, F. Winkler, B. Martineau, G. Donval, R. McLeod, E.R. Hoglund, I. Alxneit, I. Hjorth, T. Henninen, L.F. Zagonel, A. Garmannslund, 5ht2, HyperSpy v1.4, (2018). https://doi.org/10.5281/ZENODO.1407391.

[29] O.C. Hellman, J.A. Vandenbroucke, J. Rüsing, D. Isheim, D.N. Seidman, Analysis of Three-dimensional Atom-probe Data by the Proximity Histogram, Microsc. Microanal. 6 (2000) 437-444. https://doi.org/10.1007/s100050010051.

[30] X. Boulnat, M. Perez, D. Fabregue, T. Douillard, M.H. Mathon, Y. De Carlan, Microstructure evolution in nano-reinforced ferritic steel processed by mechanical alloying and spark plasma sintering, Metall. Mater. Trans. A Phys. Metall. Mater. Sci. 45 (2014) 1485-1497. https://doi.org/10.1007/s11661-013-2107-y. 
[31] N. Sallez, X. Boulnat, A. Borbély, J.L. Béchade, D. Fabrègue, M. Perez, Y. De Carlan, L. Hennet, C. Mocuta, D. Thiaudière, Y. Bréchet, In situ characterization of microstructural instabilities: Recovery, recrystallization and abnormal growth in nanoreinforced steel powder, Acta Mater. 87 (2015) 377-389. https://doi.org/10.1016/j.actamat.2014.11.051.

[32] J. Shen, Y. Li, F. Li, H. Yang, Z. Zhao, S. Kano, Y. Matsukawa, Y. Satoh, H. Abe, Microstructural characterization and strengthening mechanisms of a 12Cr-ODS steel, Mater. Sci. Eng. A. 673 (2016) 624-632. https://doi.org/10.1016/j.msea.2016.07.030.

[33] T. Chen, J.G. Gigax, L. Price, D. Chen, S. Ukai, E. Aydogan, S.A. Maloy, F.A. Garner, L. Shao, Temperature dependent dispersoid stability in ion-irradiated ferriticmartensitic dual-phase oxide-dispersion-strengthened alloy: Coherent interfaces vs. incoherent interfaces, Acta Mater. 116 (2016) 29-42. https://doi.org/10.1016/j.actamat.2016.05.042.

[34] J.S. Park, S.J. Kim, C.S. Lee, Effect of W addition on the low cycle fatigue behavior of high Cr ferritic steels, Mater. Sci. Eng. A. 298 (2001) 127-136. https://doi.org/10.1016/S0921-5093(00)01291-0.

[35] T. Narita, S. Ukai, S. Ohtsuka, M. Inoue, Effect of tungsten addition on microstructure and high temperature strength of 9CrODS ferritic steel, J. Nucl. Mater. 417 (2011) 158-161. https://doi.org/10.1016/j.jnucmat.2011.01.060.

[36] Z. Jiao, V. Shankar, G.S. Was, Phase stability in proton and heavy ion irradiated ferritic-martensitic alloys, J. Nucl. Mater. 419 (2011) 52-62. https://doi.org/10.1016/J.JNUCMAT.2011.08.020.

[37] D.A. McClintock, M.A. Sokolov, D.T. Hoelzer, R.K. Nanstad, Mechanical properties of irradiated ODS-EUROFER and nanocluster strengthened 14YWT, J. Nucl. Mater. 392 (2009) 353-359. https://doi.org/10.1016/j.jnucmat.2009.03.024. 